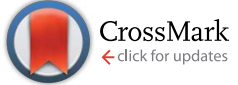

Cite this: RSC Adv., 2017, 7, 16022

Received 10th November 2016 Accepted 27th February 2017

DOI: 10.1039/c6ra26588j

rsc.li/rsc-advances

\section{Metal-organic frameworks (MOFs) as highly efficient agents for boron removal and boron isotope separation $\uparrow$}

\author{
Jiafei Lyu, ${ }^{\text {ab }}$ Hongxu Liu, ${ }^{\text {ab }}$ Jingshuang Zhang, ${ }^{\text {ab }}$ Zhouliangzi Zeng, ${ }^{\text {ab }}$ Peng Bai ${ }^{\text {ab }}$ \\ and Xianghai Guo*ab
}

The boron adsorption and isotopic separation on water-stable metal-organic frameworks (MOFs) were evaluated. These materials, to date, exhibit fairly high to highest adsorption capacities for boron. Furthermore, unprecedentedly high isotopic separation factors (S) were observed in some materials.
Global climate change and energy framework uncertainties have propelled a transition in the energy structure. Although there is a continuous and growing effort to adopt more sustainable energy systems with the ambition to reduce greenhouse gas emissions, the development of renewables still needs intensive investigation. However, the position of nuclear power keeps increasing while expanding its share in the global energy mix in spite of all its pros and cons.

Boron has two stable isotopic compositions, ${ }^{10} \mathrm{~B}$ and ${ }^{11} \mathrm{~B}$, with an abundance of $19.1-20.3 \%$ and $79.7-80.9 \%$, respectively. The ${ }^{10} \mathrm{~B}$ isotope, with a larger attenuation cross-section for thermal neutrons, is irreplaceably used in nuclear power plants for neutron shielding and in radioactive waste disposal equipment, such as the components used for compact fuel storage racks and transportation baskets. ${ }^{1,2}$ It also plays a critical role in treating cancers that cannot be controlled effectively by conventional means, which is known as boron neutron capture therapy (BNCT). ${ }^{3}$ Although methods for boron isotope separation are in high demand for the nuclear power industry and medical treatment, the separation process is practically very difficult because of the tiny differences between its isotopes. Some methods have been observed including exchange distillation, ${ }^{4-6}$ adsorption-based separation, ${ }^{7-15}$ thermal ionization mass spectrometry ${ }^{16,17}$ and the laser assisted retardation of condensation (SILARC) method, ${ }^{18-24}$ among which only isotopic exchange distillation has been successfully applied in practical ${ }^{10} \mathrm{~B}$ production. ${ }^{4}$ Except for a small separation factor of around 1.03 , disadvantages including the instability of the anisoleboron trifluoride complex, severe causticity to the equipment and insecurity as a result of the toxicity of boron trifluoride

${ }^{a}$ Department of Pharmaceutical Engineering, School of Chemical Engineering and Technology, Tianjin University, Tianjin 300350, China. E-mail: Guoxh@tju.edu.cn

${ }^{b}$ Key Laboratory of Systems Bioengineering, Ministry of Education, Tianjin University, Tianjin 300350, China

$\dagger$ Electronic supplementary information (ESI) available. See DOI: 10.1039/c6ra26588j greatly impede the process. Furthermore, technologies such as mass spectrometry and the laser are too expensive to be adopted on an industrial scale.

A promising alternative for boron isotope separation is an adsorption-based process using a boron adsorbent, which is more efficient, easier to operate and inexpensive. In addition, the increasing demand for freshwater also promotes the development of novel boron adsorbents because the ingestion of excess boron is detrimental to plants and human beings. ${ }^{25}$ For the health of human beings, the boron concentration limit in drinking water was set at $2.4 \mathrm{ppm}$ by the WHO in 2011 . However, boron concentration is usually around $5 \mathrm{ppm}$ in seawater ${ }^{26}$ and can be as high as $119 \mathrm{ppm}$ in some groundwater of active volcanic and geothermal activities. In addition, wide applications of boron compounds in industry lead to an enrichment of boron in water. ${ }^{27}$ It is also important to develop adsorbents with high boron adsorption capacities for boron removal from water.

Highly efficient adsorbents are desirable for both boron isotope separation (Section S1, ESI $\dagger$ ) and boron removal (Section S2, ESI $\dagger$ ). Various boron adsorbents, such as anion resins ${ }^{28}$ cation resins, ${ }^{7}$ boron-specific resins ${ }^{11}$ and other boron adsorbents have been explored for their isotopic separation capacity in static adsorption experiments and fixed in the chromatography column as the solid phase to study dynamic separation properties.

Among the various boron adsorbents, only $N$-methyl-D-glucamine type resins including Amberlite IRA-743 have been widely applied in boron removal, which also exhibit the highest boron isotopic separation factor $(S=1.027)^{7}$ to date. This small separation factor makes it impossible to employ chromatography to separate boron isotopes.

Metal-organic frameworks (MOFs), constructed from different metal ions and organic ligands with coordination bonds, have attracted great interest as a result of their good porosity, high specific surface and chemical tenability. A large 
number of MOFs have already been widely studied in areas such as gas storage, catalysis, optics, drug delivery, separation, and chemical sensors. ${ }^{29}$ MOFs exhibit strong potential in contaminant adsorption. Unfortunately, most metal-organic frameworks are unstable in aqueous solutions due to the waterunstable coordination bond, which limits their practical applications. In recent years, research on water-stable MOFs has made great advances, and MOFs with high water stability have been reported as effective agents for the removal of contaminants, ${ }^{30-34}$ such as ZIF-8, UiOs, and MILs. Nevertheless, investigations on MOFs as agents for boron isotope separation and adsorption have yet been reported. Herein, our goal was to identify the potential of water-stable MOFs as agents for both boron isotope separation and boron adsorption. These MOFs with good hydrothermal and chemical stability ${ }^{35,36}$ were prepared based on the reported methods. ${ }^{37-43}$ The structures and pore properties were confirmed by X-ray diffraction, scanning electron microscopy (SEM), nitrogen adsorption/ desorption and thermogravimetric analysis (Section S3-S9, ESI $\dagger$ ). Static adsorption experiments of boron acid were carried out to evaluate the boron isotope separation capacity. Seven activated MOFs were added into a $0.5282 \mathrm{~mol} \mathrm{~L}^{-1}\left(C_{0}\right)$ boric acid aqueous solution $(20 \mathrm{~mL})$ at a dosage of $5 \mathrm{~g} \mathrm{~L}^{-1}$ and the mixtures were stirred in a water bath at $25^{\circ} \mathrm{C}$ for $24 \mathrm{~h}$. Then, the MOFs were filtered and the residual solutions were analysed for the boron concentration using ICP-OES and the boron isotopic abundance $\left({ }^{10} \mathrm{~B} /{ }^{11} \mathrm{~B}\right)$ using ICP-MS. A standard boric acid aqueous solution with a known boron concentration was employed to calibrate the instrument. Each sample was analysed three times and an average value was determined.

The ${ }^{10} \mathrm{~B} /{ }^{11} \mathrm{~B}$ abundance of the initial boric acid aqueous solution $\left(\alpha_{0}\right)$ was 0.24779 and the ${ }^{10} \mathrm{~B} /{ }^{11} \mathrm{~B}$ abundance and boron concentration of the residual boric acid solution after the adsorption experiments are summarized in Fig. S8 (ESI $\dagger$ ). The boron isotope separation factors and boron adsorption capacities of all seven MOFs were calculated (Section S10, ESI $\dagger$ ) and shown in Fig. 1 and 2. When compared with other boron adsorbents (Table S2, ESI $\dagger$ ), all the seven MOFs perform well for boron adsorption. In Fig. 1, the adsorption capacities were compared with a commercial Amberlite IRA-743 resin and waste

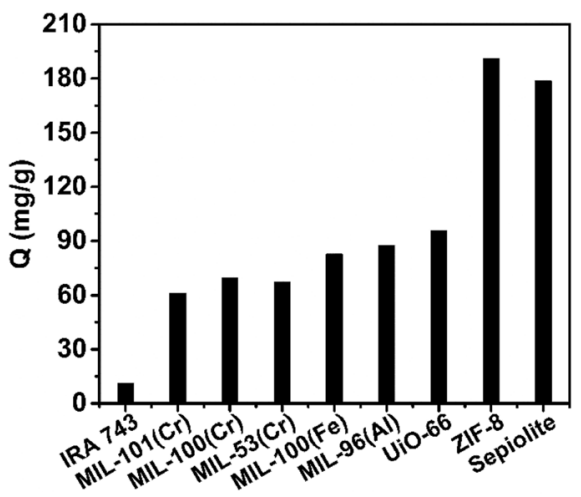

Fig. 1 The boron adsorption capacities of seven MOFs compared with Amberlite IRA-743 and waste sepiolite.

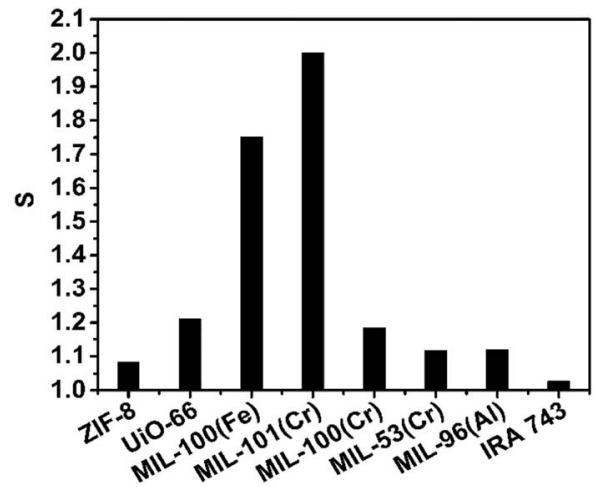

Fig. 2 The boron isotopic separation factors of seven MOFs and Amberlite IRA-743.

sepiolite, which has the highest capacity among the previously reported boron adsorbents. All of them exhibit much higher adsorption capacity than Amberlite IRA-743, particularly ZIF-8, which exhibits a boron adsorption capacity of $191 \mathrm{mg} \mathrm{g}^{-1}$, which is, to the best of our knowledge, the highest capacity ever reported. The other six MOFs have similar boron adsorption capacities as UiO-66 > MIL-96(Al) > MIL-100(Fe) > MIL-100(Cr) > MIL-53(Cr) > MIL-101(Cr), which are also much higher than the capacity of Amberlite IRA-743 resin. The Dubinin-Radushkevich (D-R) isotherm model, ${ }^{44}$ which is applicable for both homogeneous and heterogeneous surfaces, was used to describe boron sorption on ZIF-8. Linear fitting based on the D-R model estimated the maximum amount of boron that can be adsorbed by ZIF- 8 to be $234.6 \mathrm{mg} \mathrm{g}^{-1}$. The adsorbed ZIF-8 and adsorbed MIL-101(Cr) were characterized with XRD to observe their stability. It can be observed from the spectra (Fig. 3) that the structure of ZIF-8 was completely changed after boron adsorption, while MIL-101(Cr) retained its structure under the adsorption conditions.

Based on the boron isotopic abundance of the residual solutions shown in Fig. S8 (ESI $\dagger$ ), it can be observed that the boron isotopic abundance $\left({ }^{10} \mathrm{~B} /{ }^{11} \mathrm{~B}\right)$ of all the residual solutions was higher than that of the initial boron solution (0.24779), which suggests that ${ }^{10} \mathrm{~B}$ was enriched in the solution phase and ${ }^{11} \mathrm{~B}$ was enriched in the adsorbents during the adsorption process. It was also proven that the MOFs have good selectivity between the boron isotopes $\left({ }^{10} \mathrm{~B}\right.$ and $\left.{ }^{11} \mathrm{~B}\right)$.

The boron isotopic separation factors were compared with commercial Amberlite IRA-743 and are shown in Fig. 2. All
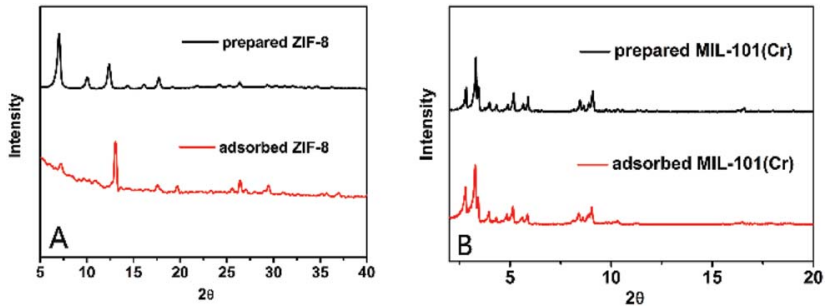

Fig. 3 A comparison of the XRD spectra between the prepared materials and adsorbed materials: (A) ZIF-8, (B) MIL-101(Cr). 
seven metal-organic frameworks exhibit higher separation factors than the conventional boron-specific adsorbent Amberlite IRA-743 (1.022) ${ }^{45}$ and isotopic exchange distillation factors (1.039) ${ }^{6}$. Among them, MIL-101(Cr) and MIL-100(Fe) exhibit boron isotope separation factors of 2.00 and 1.75, respectively. It is worth mentioning that MIL-101(Cr) has by far the highest boron isotope separation factor, which is an astonishing 35 fold increase of the present best result $(1.027)^{46}$ held by $N$-methyl-D-glucamine type resin. The adsorption separation can be operated under mild conditions with aqueous solutions of boric acid. Compared with a traditional chemical exchange distillation process, it will strongly improve the separation efficiency, reduce the cost of equipment and strengthen the safety.

Furthermore, the effects of temperature and $\mathrm{pH}$ on boron adsorption and isotopic separation were investigated. Four temperatures $\left(25^{\circ} \mathrm{C}, 35{ }^{\circ} \mathrm{C}, 45^{\circ} \mathrm{C}\right.$ and $\left.55{ }^{\circ} \mathrm{C}\right)$ and five different pHs were investigated in this study. The results obtained for the adsorption capacity and isotopic separation factors are summarized in Fig. 4. It was found that the boron adsorption capacity increased upon increasing the temperature (Fig. 4A), which demonstrated that boron adsorption on MIL-101(Cr) was an endothermic process. On the contrary, the boron isotopic separation factor decreased significantly upon increasing the temperature. This can be attributed to the stronger interaction between boric acid and MIL-101(Cr) at higher temperature, which decreases the selectivity for the two isotopes. In Fig. 4B, it can be observed that the boron adsorption capacity displayed an increasing trend with increasing the $\mathrm{pH}$ from 2.05 to 6.91, up to $146.1 \mathrm{mg} \mathrm{g}^{-1}$, then decreased with a further increase in $\mathrm{pH}$. Similar to the study of temperature, the isotopic separation exhibited an opposite trend.

To facilitate understanding of mechanism for the boron adsorption process, ${ }^{11} \mathrm{~B}$ MAS NMR spectroscopy (Fig. 5) was performed to evaluate the chemical environment of boron in the adsorbed MIL-101(Cr). The structure of $\mathrm{B}(\mathrm{OH})_{3}$ dominates in the original boric acid aqueous solution with a peak at $19.40 \mathrm{ppm}$. After adsorption, the ${ }^{11} \mathrm{~B}$ MAS NMR peaks for both adsorbed MIL-101(Cr) and MIL-100(Fe) move to a higher field, with the MIL-101(Cr) peak at $0.78 \mathrm{ppm}$ and the MIL-100(Fe) peak at $3.98 \mathrm{ppm}$, which suggests that chemical adsorption mainly occurs in the adsorption process.

The as-synthesized and adsorbed MIL-101(Cr) were also characterized using X-ray photoelectron spectroscopy (XPS) measurements to observe the interaction between boric acid
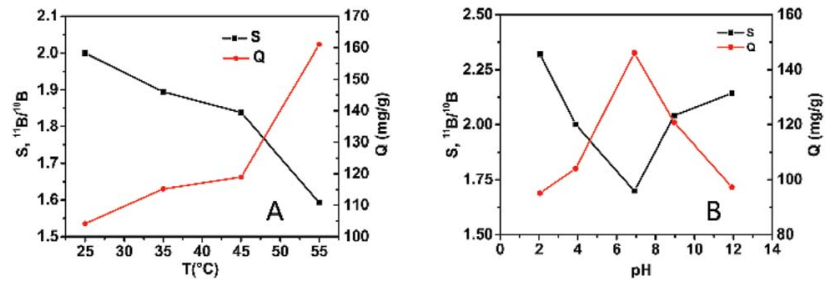

Fig. 4 The effect of temperature $(\mathrm{A})$ and $\mathrm{pH}(\mathrm{B})$ on boron adsorption and isotope separation on MIL-101(Cr).

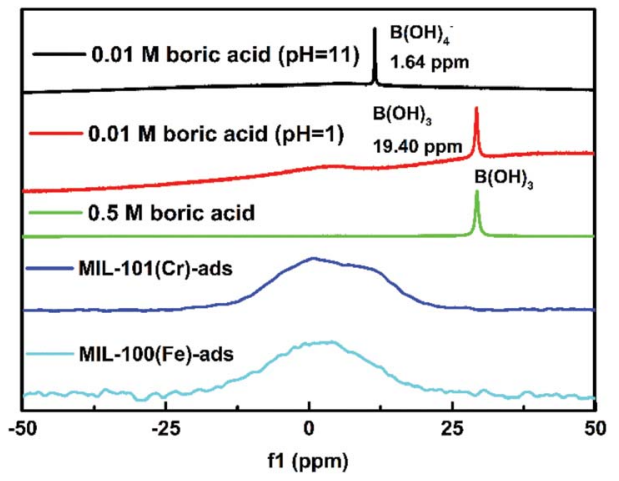

Fig. 5 The ${ }^{11} B$ NMR spectra of aqueous solutions of boric acid and the adsorbed MIL-101(Cr).

and the adsorbent. The XPS patterns (Fig. 6) show the change in binding energy at the $\mathrm{Cr} 2 \mathrm{p}$ peaks after boron adsorption on MIL-101(Cr), which indicates the interactions between boric acid and the metal sites.

To further explore the separation mechanism, an adsorption simulation with molecular dynamics was employed. We simulated the boric acid adsorption density distribution ${ }^{47}$ (Fig. S11 $\dagger$ ) in both pentagonal and hexagonal windows of MIL-101(Cr). It can be proven that boric acid was adsorbed in the tetrahedron cages irrespective of whether the window was pentagonal or hexagonal. This result can be attributed to boric acid being closer to the metal sites in the tetrahedron cages and further confirms the interaction between boric acid and the metal sites. A similar observation was made for ZIF-8 in which boron adsorption was a chemical process, which mainly occurred between the boron and zinc sites (Section 12, ESI $\dagger$ ).

The regeneration and recyclability of materials are crucial for practical applications. Both hydrochloric acid (5\%) and hydrofluoric acid $(0.4 \%)$ were employed as regeneration agents. However, it turned out that only part of the boric acid can be eluted from the adsorbed MIL-101(Cr). The adsorbed material cannot be regenerated completely.

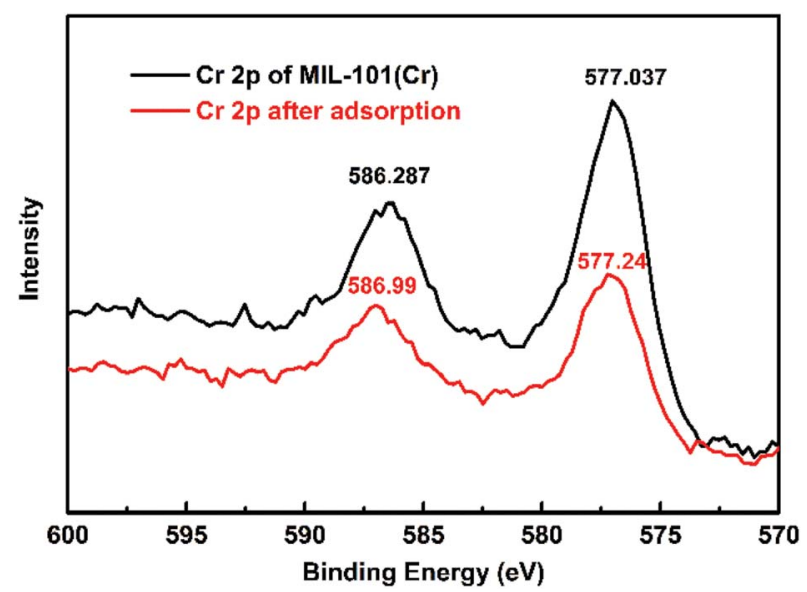

Fig. 6 The XPS patterns of the as-synthesized and adsorbed MIL101(Cr). 
In conclusion, we examined the boron isotope separation and boron adsorption capacity of seven water-stable MOFs. All of them exhibit higher separation factors than the previously reported techniques, particularly MIL-100(Fe) and MIL-101(Cr). The separation factor of MIL-101(Cr) is 2.00, which is significant in the boron isotope separation process. In addition, all of the MOFs demonstrated excellent performance compared with other boron adsorbents, particularly ZIF-8. The high isotope separation and boron removal capacities make it possible that both problems, boron removal and isotopic separation, can be solved in a dual step process. Further research on both boron adsorption and the isotope separation capacity of other waterstable MOFs and a deeper understanding of the separation mechanism are highly desirable.

\section{Acknowledgements}

This study was supported by the National Natural Science Foundation of China (No. 21202116), Independent Innovation Foundation of Tianjin University (2016XZC-0071) and Natural Science Foundation of Tianjin (16JCYBJC20300).

\section{Notes and references}

1 M. Zawisky, M. Basturk, R. Derntl, F. Dubus, E. Lehmann and P. Vontobel, Appl. Radiat. Isot., 2004, 61, 517-523.

2 K. N. Leung, J. M. Verbeke and J. Vujic, Appl. Radiat. Isot., 2000, 53, 801-809.

3 W. S. Kiger III and M. R. Palmer, Radiat. Res., 2001, 155, 611618.

4 M. Abdollahi and S. J. Ahmadi, Chem. Eng. Process., 2014, 76, 26-32.

5 F. Wei, W. Zhang, M. Han, L. Han, X. Zhang and S. Zhang, Chem. Eng. Process., 2008, 47, 17-21.

6 T. Lin, W. Zhang and L. Wang, J. Phys. Chem. A, 2009, 113, 7267-7274.

7 H. Zhao, R. Gao and P. Bai, Asian J. Chem., 2014, 26, 21872190.

8 M. Musashi, M. Matsuo, T. Oi and M. Nomura, J. Nucl. Sci. Technol., 2006, 43, 461-467.

9 M. Musashi, T. Oi, M. Matsuo and M. Nomura, J. Chromatogr. A, 2008, 1201, 48-53.

10 A. Sonoda, Y. Makita and T. Hirotsu, J. Nucl. Sci. Technol., 2006, 43, 437-440.

11 A. Sonoda, Y. Makita and T. Hirotsu, J. Nucl. Sci. Technol., 2008, 45, 117-121.

12 T. Qi, A. Sonoda, Y. Makita, H. Kanoh, K. Ooi and T. Hirotsu, J. Appl. Polym. Sci., 2002, 83, 2374-2381.

13 E. Lemarchand, J. Schott and J. Gaillardet, Geochim. Cosmochim. Acta, 2005, 69, 3519-3533.

14 J. Xiao, Y. Xiao, C. Liu, Z. Zhao, M. He and C. Liang, Chin. Sci. Bull., 2009, 54, 3090-3100.

15 L. Zhou, K. Wu, W. Qin, G. Wang, D. Fu and W. Fei, Sci. China: Chem., 2015, 58, 1187-1192.

16 A. Sonoda, Y. Makita, K. Ooi and T. Hirotsu, J. Nucl. Sci. Technol., 2002, 39, 295-302.
17 Q. Xu, Y. Dong, H. Zhu and A. Sun, Int. J. Anal. Chem., 2015, 364242.

18 M. Joseph and P. Manoravi, Appl. Phys. A: Mater. Sci. Process., 2003, 76, 153-156.

19 M. Joseph, N. Sivakumar, P. Manoravi and R. Balasubramanian, Rapid Commun. Mass Spectrom., 2004, 18, 231-234.

20 K. Lyakhov and H.-J. Lee, J. Nanosci. Nanotechnol., 2015, 15, 8502-8507.

21 K. A. Lyakhov and H. J. Lee, Appl. Phys. B: Lasers Opt., 2013, 111, 261-272.

22 K. A. Lyakhov and H. J. Lee, Ann. Nucl. Energy, 2013, 54, 274280.

23 X. Mao, A. A. Bol'shakov, D. L. Perry, O. Sorkhabi and R. E. Russo, Spectrochim. Acta, Part B, 2011, 66, 604-609.

24 B. Yee, K. C. Hartig, P. Ko, J. McNutt and I. Jovanovic, Spectrochim. Acta, Part B, 2013, 79-80, 72-76.

25 N. Geffen, R. Semiat, M. S. Eisen, Y. Balazs, I. Katz and C. G. Dosoretz, J. Membr. Sci., 2006, 286, 45-51.

26 H. Demey-Cedeno, M. Ruiz, J. A. Barron-Zambrano and A. M. Sastre, J. Chem. Technol. Biotechnol., 2014, 89, 934-940.

27 G. Zelmanov and R. Semiat, Desalination, 2014, 333, 107117.

28 M. Aida, Y. Fujii and M. Okamoto, Sep. Sci. Technol., 1986, 21, 643-654.

29 H. Furukawa, K. E. Cordova, M. O'Keeffe and O. M. Yaghi, Science, 2013, 341, 1230444.

30 A. A. Adeyemo, I. O. Adeoye and O. S. Bello, Toxicol. Environ. Chem., 2012, 94, 1846-1863.

31 Y. Wu, H. Y. Chen, D. F. Liu, J. Xiao, Y. Qian and H. X. Xi, ACS Appl. Mater. Interfaces, 2015, 7, 5775-5787.

32 K. Xie, C. H. Shan, J. S. Qi, S. Qiao, Q. S. Zeng and L. Y. Zhang, Desalin. Water Treat., 2015, 54, 654-659.

33 X. Y. Lan, H. H. Zhang, P. Bai and X. H. Guo, Microporous Mesoporous Mater., 2016, 231, 40-46.

34 H. H. Zhang, X. Y. Lan, P. Bai and X. H. Guo, Chem. Eng. Res. Des., 2016, 111, 127-137.

35 N. C. Burtch, H. Jasuja and K. S. Walton, Chem. Rev., 2014, 114, 10575-10612.

36 N. u. Qadir, S. A. M. Said and H. M. Bahaidarah, Microporous Mesoporous Mater., 2015, 201, 61-90.

37 N. L. Torad, M. Hu, Y. Kamachi, K. Takai, M. Imura, M. Naito and Y. Yamauchi, Chem. Commun., 2013, 49, 2521-2523.

38 M. J. Katz, Z. J. Brown, Y. J. Colon, P. W. Siu, K. A. Scheidt, R. Q. Snurr, J. T. Hupp and O. K. Farha, Chem. Commun., 2013, 49, 9449-9451.

39 J. W. Yoon, Y. K. Seo, Y. K. Hwang, J. S. Chang, H. Leclerc, S. Wuttke, P. Bazin, A. Vimont, M. Daturi, E. Bloch, P. L. Llewellyn, C. Serre, P. Horcajada, J. M. Greneche, A. E. Rodrigues and G. Ferey, Angew. Chem., Int. Ed. Engl., 2010, 49, 5949-5952.

40 C. Serre, F. Millange, C. Thouvenot, M. Nogues, G. Marsolier, D. Louer and G. Ferey, J. Am. Chem. Soc., 2002, 124, 1351913526.

41 G. Ferey, C. Mellot-Draznieks, C. Serre, F. Millange, J. Dutour, S. Surble and I. Margiolaki, Science, 2005, 309, 2040-2042.

42 G. Férey, C. Serre, C. Mellot-Draznieks, F. Millange, S. Surblé, J. Dutour and I. Margiolaki, Angew. Chem., 2004, 116, 6456-6461. 
43 T. Loiseau, L. Lecroq, C. Volkringer, J. Marrot, G. Ferey, M. Haouas, F. Taulelle, S. Bourrelly, P. L. Llewellyn and M. Latroche, J. Am. Chem. Soc., 2006, 128, 10223-10230.

44 Ö. Kaftan, M. Açıkel, A. E. Eroğlu, T. Shahwan, L. Artok and C. Ni, Anal. Chim. Acta, 2005, 547, 31-41.
45 T. Oi, H. Shimazaki, R. Ishii and M. Hosoe, Sep. Sci. Technol., 1997, 32, 1821-1834.

46 Y. M. K. O. Akinari Sonoda, N. Takagi and T. Hirotsu, Bull. Chem. Soc. Jpn., 2000, 73, 1131-1133.

47 B. Y. Liu, Y. B. Wu, D. F. Liu, Y. Wu, H. X. Xi and Y. Qian, Phys. Chem. Chem. Phys., 2013, 15, 2741-2748. 